\title{
Application of Hot-wire Method for Measuring Thermal Conductivity of Fine Ceramics
}

\author{
Shangxi WANG *, Dan ZHANG, Gaoshan LIU, Wenjun WANG, Mengxia HU \\ College of Engineering, Shantou University, Guangdong, China, 515063 \\ cross $^{\text {ref }}$ http://dx.doi.org/10.5755/j01.ms.22.4.12543
}

\author{
Received 23 June 2015; accepted 11 October 2015
}

\begin{abstract}
Ceramic substrate is preferred in high density packaging due to its high electrical resistivity and moderate expansion coefficient. The thermal conductivity is a key parameter for packaging substrates. There are two common methods to measure the thermal conductivity, which are the hot-wire method and the laser-flash method. Usually, the thermal conductivities of porcelain is low and meet the measurement range of hot-wire method, and the measured value by hotwire method has little difference with that by laser-flash method. In recent years, with the requirement of high-powered LED lighting, some kinds of ceramic substrates with good thermal conductivity have been developed and their thermal conductivity always measured by the means of laser flash method, which needs expensive instrument. In this paper, in order to detect the thermal conductivity of fine ceramic with convenience and low cost, the feasibility of replacing the laser flash method with hot wire method to measure thermal conductivity of ceramic composites was studied. The experiment results showed that the thermal conductivity value of fine ceramics measured by the hot-wire method is severely lower than that by the laser-flash method. However, there is a positive relationship between them. It is possible to measure the thermal conductivity of fine ceramic workpiece instantly by hot-wire method via a correction formula. Keywords: thermal conductivity, hot-wire method, laser-flash method, ceramic substrate.
\end{abstract}

\section{INTRODUCTION}

In recent years, the high-power LED lighting has been rapidly developed as the fourth generation of illumination. The heat dissipation capacity of LED plays a key role on the lifetime of LED lamps. The substrate is one of the most effective dissipation channels for LED lamps. Fine ceramics have been paid much attention to as LED packaging substrate, due to their advantages of good heatconducting property, low thermal expansion coefficient and large electric resistance [1]. So far, some fine ceramic substrate could be sintered below $900{ }^{\circ} \mathrm{C}$ and has much higher thermal conductivity than that of the resin substrate. For example, the thermal conductivity of $\mathrm{Al}_{2} \mathrm{O}_{3}$ substrate materials sintered at low temperature is about $2-4 \mathrm{Wm}^{-1} \mathrm{~K}^{-1}$ and the thermal conductivity of AlN substrate materials sintered at low temperature is about $10 \mathrm{Wm}^{-1} \mathrm{~K}^{-1}$ [2]. Furthermore, the thermal conductivities of some ceramic composites are as high as dozens or even hundreds of $\mathrm{Wm}^{-1} \mathrm{~K}^{-1}$ [3]. With the extensive study and application of ceramic substrate in the lab and industry, it urgently requires a simple and fast thermal conductivity measurement for ceramic materials.

The transfer of heat from high temperature area to low temperature area motivated by the temperature difference is called heat transmission. The basic transmission mechanism contains heat convection, radiation and conduction. The mode of heat convection mainly exists both in gaseous and liquid. The heat radiation mode mainly exists in high temperature objects, while solids mainly dominated by the mode of heat conduction. Different materials have different way in heat conduction. Free

\footnotetext{
${ }^{*}$ Corresponding author. Tel.: +86-075482518903.

E-mail address: sxwang@stu.edu.cn (S. Wang)
}

electron takes a domination role in metal while insulator and most of the semiconductors are dominated by lattice vibration. For ceramic materials, heat conduction is the primary way to transmit the heat, and the ability of heat conduction depends on thermal conductivity property of the materials, which is indexed by the thermal conductivity coefficient. The bigger thermal conductivity value of the matter is, the better heat conduction ability it behaves.

Nowadays, several techniques are available to obtain the thermal conductivity of different materials. The hotwire method is considered to be an effective and accurate mean to determine the thermal conductivity for refractory materials. Depending on the study of thermal conductivity of various materials, much works has been done for the application of hot-wire technique. M.J.Assael et al [4] modified the hot-wire technique and uesd it to accurate determine the thermal property of Pyroceram 9606 up to $420 \mathrm{~K}$ and the Pyroceram 9606 was regarded as a European Commission certified thermal-conductivity reference materials. Santos [5] proposed that the hot-wire method may be applicable for materials with high thermal conductivity range from 0.04 to $14 \mathrm{Wm}^{-1} \mathrm{~K}^{-1}$ and it is possible to be applied for electrical conducting materials. Meanwhile, the hot wire method was also adopted as determination of the thermal properties of melt polymers materials [6]. Hot-wire method is one of the most simple and convenient transient-state methods and it was applied to measure the thermal conductivity range lower than $25 \mathrm{Wm}^{-1} \mathrm{~K}^{-1}$ [7]. While, for the materials with high thermal conductivity, the laser flash method is the most ideal measuring technique, because of its wide applied range and high precision. However, the cost of laser flash technology is much higher and its requirements for sample's preparation is more complicated, compared with the hot- 
wire method. Moreover, it needs high expensive laser experiment for the laser-flash technology. In this paper, in order to detect the thermal conductivity of fine ceramic with convenience and low cost, the feasibility of replacing the laser flash method with hot wire method to measure thermal conductivity of ceramic workpiece was studied. The hot-wire method was applied to estimate the thermal conducting ability of some ceramic substrate materials (i.e. $\quad \mathrm{Al}_{2} \mathrm{O}_{3} /$ glass/AlN $\mathrm{A}_{\mathrm{p}}, \quad \mathrm{Al}_{2} \mathrm{O}_{3} /$ glass/whisker and $\mathrm{Al}_{2} \mathrm{O}_{3}$ /glass/fiber) and the tested results by hot-wire method were compared with that by laser-flashed method. Meanwhile, the feasibility of applying hot-wire method to measure thermal conductivity of fine ceramic materials was discussed.

\section{MATERIALS AND EXPERIMENT}

\subsection{Materials and preparation}

$\mathrm{ZnO}-\mathrm{SiO}_{2}-\mathrm{CaO}$ glass $\left(\mathrm{ZSC}, \quad \mathrm{T}_{\mathrm{g}}=853 \mathrm{~K}\right.$, $\mathrm{D}_{50}=1.03 \mu \mathrm{m}, \mathrm{CTE}=0.6 \mathrm{Wm}^{-1} \mathrm{~K}^{-1}$, South China Institute of Fine Ceramic, Foshan, China) was introduced as bonding agent. $\alpha-\mathrm{Al}_{2} \mathrm{O}_{3}\left(\mathrm{D}_{50}=5.68 \mu \mathrm{m}\right.$, Sinocera, Fujian, China, $99.9 \%$ ) was taken as the basic ceramic filler. Three types of reinforcing phases (powder, whisker and fiber) were added in the ceramic composites. AlN powder with high conductivity was chosen as the representative type of powder type $\left(\mathrm{AlN}_{\mathrm{p}}, \mathrm{D}_{50}=2.86 \mu \mathrm{m}\right.$, Sinocera, Fujian, China). AlN whisker with excellent thermal conductivity $\left(\mathrm{AlN}_{\mathrm{w}}, \mathrm{D}=1 \mu \mathrm{m}\right.$, aspect ratio $=10-40$, Sinocera, Fujian, China) and alumina borate whisker with poor thermal conductivity $\left(\mathrm{AB}_{\mathrm{w}}, \mathrm{D}=0.3-2.0 \mu \mathrm{m}\right.$, aspect ratio $>20$, China) were chosen as the two extreme representatives. Copper fiber $\left(\mathrm{Cu}_{\mathrm{f}}, \mathrm{D}=1 \mu \mathrm{m}\right.$, aspect ratio $\left.=10-40,99 \%\right)$ and carbon fiber $\left(\mathrm{C}_{\mathrm{f}}, \mathrm{D}=10 \mu \mathrm{m}\right.$, aspect ratio $>10$, Japan $)$ were introduced as reinforcing fiber materials.

According to the compositions listed in Table 1, materials were mixed respectively in ethanol for $2 \mathrm{~h}$. The mixtures were then completely dried in an oven at $80{ }^{\circ} \mathrm{C}$. The dried powders were moulded into the die and pressed at $880{ }^{\circ} \mathrm{C}$ under pressure of $25 \mathrm{MPa}$ in nitrogen atmosphere for $45 \mathrm{~min}$.

\subsection{Thermal conductivity evaluation}

Based on the $\alpha-\mathrm{Al}_{2} \mathrm{O}_{3}$ ceramics, three groups of composites were designed according to the shapes of enhancing phases (powder, whisker, fiber), i.e., $\mathrm{Al}_{2} \mathrm{O}_{3} /$ glass/ $\mathrm{AlN}_{\mathrm{p}}$, $\mathrm{Al}_{2} \mathrm{O}_{3} /$ glass/whisker and $\mathrm{Al}_{2} \mathrm{O}_{3} /$ glass/ fiber, as seen in Table 1 .

Table 1. Compositions of ceramic samples (vol \%)

\begin{tabular}{|c|c|c|c|c|c|}
\hline \multicolumn{2}{|c|}{$\mathrm{Al}_{2} \mathrm{O}_{3} / 30$ glass $/ \mathrm{AlN}_{\mathrm{p}}$} & \multicolumn{2}{|c|}{$\mathrm{Al}_{2} \mathrm{O}_{3} / 30$ glass/whisker } & \multicolumn{2}{|c|}{$\mathrm{Al}_{2} \mathrm{O}_{3} / 30$ glass/fiber } \\
\hline No. & powder & No. & whisker & No. & fiber \\
\hline $\mathrm{S} 1$ & $10 \mathrm{AlN}$ & $\mathrm{S} 4$ & $10 \mathrm{AB}_{\mathrm{w}}$ & $\mathrm{S} 10$ & $10 \mathrm{C}_{\mathrm{f}}$ \\
\hline $\mathrm{S} 2$ & $30 \mathrm{AlN}$ & $\mathrm{S} 5$ & $30 \mathrm{AB}_{\mathrm{w}}$ & $\mathrm{S} 11$ & $20 \mathrm{C}_{\mathrm{f}}$ \\
\hline $\mathrm{S} 3$ & $50 \mathrm{AlN}$ & $\mathrm{S} 6$ & $50 \mathrm{AB}_{\mathrm{w}}$ & $\mathrm{S} 12$ & $30 \mathrm{C}_{\mathrm{f}}$ \\
\hline- & - & $\mathrm{S} 7$ & $10 \mathrm{AlN}_{\mathrm{w}}$ & $\mathrm{S} 13$ & $10 \mathrm{Cu}_{\mathrm{f}}$ \\
\hline- & - & $\mathrm{S} 8$ & $30 \mathrm{AlN}_{\mathrm{w}}$ & $\mathrm{S} 14$ & $20 \mathrm{Cu}_{\mathrm{f}}$ \\
\hline- & - & $\mathrm{S} 9$ & $50 \mathrm{AlN}_{\mathrm{w}}$ & $\mathrm{S} 15$ & $30 \mathrm{Cu}_{\mathrm{f}}$ \\
\hline
\end{tabular}

In this research, the thermal conductivity of the sample was firstly measured by hot-wire method. The measurement equipment (TC3000) for transient hot-wire method is made by Xiatech Company, China. Each sample was measured for five times and the average value was taken as the final data. In order to ensure the accuracy of the test results, the hot-wire device was corrected beforehand. At first, started the device and waited for $10 \mathrm{~min}$ to make the system stable. Then, took the standard sample (Pyrex 7740 ) was used to correct the system until the deviation between tested data and nominal data kept in $\pm 1 \%$. Then, sample's thermal conductivity was measured after the correction.

The testing by laser flash method was taken in the State Key Laboratory of Advanced Technology for Material Synthesis and Processing, Wuhan University of Technology, China. The samples were machined into pellets $(\Phi 30 \mathrm{~mm} \times 5 \mathrm{~mm}$ and $\Phi 12.7 \mathrm{~mm} \times 3 \mathrm{~mm})$. Then, their thermal properties were measured by laser-flash technique measurement equipment (LFA427, Netzsch, Germany).

\section{MEASUREMENT PRINCIPLES}

Thermal conductivity is taken as an index to evaluate the heat conducting property of ceramic substrate It is generally represented symbolically by $\lambda$ and is defined as that the caloric passes per unit area with per unit thickness in per unit time when the temperature difference between two side is $1^{\circ} \mathrm{C}$. Generally, the methods of thermal conductivity measurement are classified into steady state and transient state. The steady state method is based on the balance condition hypothesis that the heat transmission rate is equal to the heat dissipation rate, which mainly includes the plate method, the heat flow meter method, the guarded plate method and the hot-box method, etc. The steady-state method is an attractive choice owing to its simple principle, low cost and easy operation. However, it needs a long measurement cycle and performs in the complicated experimental condition, which does not apply in wet materials [8]. The transient-state method is based on the principle that the temperature of sample changes along with the variation of time so that the thermal conductivity of sample could be measured according to the temperature variation and other necessary parameters of one point inside the sample. Transient-state method could be divided into contact transient-state method and non-contact transient-state method. Contact transient-state method mainly includes the hot-wire method, the heat probe method, the hot strip method and the plane source method. Non-contact transient-state method mainly contains the laser-flash method which has the advantages of rapid and accurate.

\subsection{Principle of hot-wire technology}

The hot-wire method was firstly proposed by Schieirmacher in 1888, it was described as an absolute, non-steady and direct technique [9]. It was applied to measure thermal conductivity of liquid at early years [10]. In 1960, Haupin [11] first used it to measure the thermal conductivity of ceramic materials. The measurement process by hot-wire method is as follows: first of all, prepare a resistance wire (i.e. hot wire) which possesses the characteristic of constant heat flux and even heat release, then place it in the middle of two same isotropous infinite mediums at uniform temperature; second, measure 
the temperature variation of the hot wire or sample in a period of time so as to confirm some physical parameters of the sample. Equation (1) shows the Fourier Equation [12]:

$$
\begin{aligned}
& \frac{\partial T}{\partial t}=\alpha \nabla^{2} T ; \\
& \alpha=\frac{\lambda}{p C_{p}},
\end{aligned}
$$

where $T$ is the temperature $(\mathrm{K}), t$ is time $(\mathrm{s}) ; \alpha$ is the thermal diffusion coefficient of sample $\left(\mathrm{mm}^{2} \mathrm{~s}^{-1}\right) ; \lambda, \rho, C_{p}$ is the thermal conductivity $\left(\mathrm{Wm}^{-1} \mathrm{~K}^{-1}\right)$, density $\left(\mathrm{g} \mathrm{cm}^{-3}\right)$ and specific heat at constant pressure $\left(\mathrm{J} \mathrm{g}^{-1} \mathrm{~K}^{-1}\right)$ of tested material, respectively.

With an hypothesis of that the physical parameters of sample are constants in heating process, notes the initial temperatures of liner heat source and tested sample as $T_{0}$, while notes the temperature of random place in random time as $\Delta T$. the relationship between $T_{0}$ and $\Delta T$ can be defined as :

$$
\Delta T(\mathrm{r}, \mathrm{t})=T(r, t)-T_{0} ;
$$

Eq. 1 could also be expressed as:

$\frac{\partial T(\mathrm{r}, \mathrm{t})}{\partial t}=\alpha \nabla^{2}(\Delta T(r, t))$.

The initial condition and boundary condition as follows:

$\Delta T(r, t)=0, t \leq 0$

$\lim _{r \rightarrow 0}\left(r \frac{\partial T}{\partial t}\right)=-\frac{q}{2 \pi \lambda}=$ const

$\lim _{r \rightarrow \infty} \Delta T(r, t)=0, t \geq 0$,

where, $q$ is the heating power in unit length of heat source. On the supposition of that the physical parameters like $\alpha$, $\lambda, q$ and $C_{p}$ are constant, when the radius of hot wire $\left(r_{0}\right)$ is small enough and the time $(t)$ is long enough, bases on the polynomial expansion of Eq. 4, the temperature rise of hot wire can be written as:

$$
\Delta T_{i d}\left(\mathrm{r}_{0}, \mathrm{t}\right)=\frac{q}{4 \pi \lambda} \ln t+\frac{q}{4 \pi \lambda} \ln \frac{4 \alpha}{r_{0}^{2} C}=A \ln t+B,
$$

where

$$
A=\frac{q}{4 \pi \lambda}, B=A \ln \frac{4 \alpha}{r_{0}^{2} C} \text {. }
$$

It could be found based on Eq. 8, the temperature rise $(\Delta T)$ has a linear relation with $\ln t$, in hence, the thermal conductivity $(\lambda)$ could be obtained by the slope $(A)$ and intercept $(B)$ of the $\Delta T-\ln t$ curve, resulting in the following expression:

$$
\lambda=\frac{q}{4 \pi A}=\frac{q}{4 \pi\left(d \Delta T_{i d} / d \ln t\right)} .
$$

The test principle of hot wire technique is based on Eq.10. And the thermal conductivity of tested materials could be calculated with known heating power $(q)$ and the logarithmic relationship between temperature rise and time.

Although the test error for nonmetal solid materials by using hot-wire method is as high as 5\%-10\% [13], hotwire method becomes more and more popular and mature in laboratory and industry due to its simple requirement of sample preparation, quick testing and low equipment expense. It is not only fit for dry materials but also wet materials, as well as high-temperature refractory materials. Hot-wire method is even considered as the most precise method for thermal conductivity measuring of fluid [14].

\subsection{Principle of laser-flash technology}

The laser-flash method was proposed by Parker in 1961 [15], and it's a kind of transient-state method also. In fact, the parameter measured by laser method is called the thermal diffusion coefficient. The thermal conductivity value should be calculated by Eq. 11 with a known specific heat capacity and volume density of the sample. The test process could be divided into four parts. Firstly, place the sample in a furnace and keep the furnace temperature in a certain value. Secondly, the laser pulse lights the bottom surface of the sample. Thirdly, use the infrared detector detecting temperature on the top surface of the sample in order to obtain the half maximum temperature rise time $\left(t_{50}\right)$. Finally, calculate the thermal diffusion coefficient $\alpha$ according to the Fourier Eq. 12.

$$
\begin{aligned}
& \lambda(T)=\alpha(T) \cdot \rho(T) \cdot C_{p}(T), \\
& \alpha=1.38 L^{2} / \pi^{2} t_{50} .
\end{aligned}
$$

where, $\lambda$ is the thermal conductivity $\left(\mathrm{Wm}^{-1} \mathrm{~K}^{-1}\right) ; \alpha$ is the thermal diffusion coefficient $\left(\mathrm{mm}^{2} \mathrm{~s}^{-1}\right) ; C_{p}$ is specific heat capacity $\left(\mathrm{J} \mathrm{g}^{-1} \mathrm{~K}^{-1}\right) ; \rho$ is the volume density $\left(\mathrm{g} \mathrm{cm}^{-3}\right)$; $L$ is the thickness of the sample $(\mathrm{m})$.

The specific heat capacity $\left(C_{p}\right)$ could be measured by the Laser flash instrument or determined by DSC method or obtained from the literature date, in hence, DSC method is the most precise way, whose test error is lower than $1 \%$.

Laser-flash technique is such a method, which has broad measurement range $\left(0.1-2000 \mathrm{~W} \mathrm{~m}^{-1} \mathrm{~K}^{-1}\right)$ and wide measurement temperature $\left(-110-2000{ }^{\circ} \mathrm{C}\right)$. It is available for various kinds of samples, such as solid, liquid, powder and film, especially for materials with high thermal conductivity [16]. However, the sample size is generally restricted to $12.7 \mathrm{~mm}$ or $20 \mathrm{~mm}$ in diameter and $2.5-8 \mathrm{~mm}$ thick for laser-flash method. The thickness of sample should meet the demand that half temperature rise time (i.e. $t_{50}$ ) should exceed 50 times of the pulse width.

Laser-flash method has the advantages of accurate and fast. However, the apparatus for laser-flash method is too expensive and preparing procedure for experiment is too complicated because of its high strict limits for the testing sample. Therefore, laser-flash method is used mostly in lab research.

\section{EXPERIMENTAL RESULTS}

Generally, thermal conductivity value measured by laser method is quite accurate because it is influenced slightly by operation process and measurement environment. Most researchers prefer it for thermal conductivity measurement. Nevertheless, laser measuring instrument is much more expensive. Moreover, its requirement for the sample size is quite strict, which would lead to inconvenience for preparing sample. For the thermal conductivity measurement of resin or refractory materials, hot-wire method has been widely used owing to 
its low cost and convenient measure procedure. According to the ISO standard, the hot-wire method is used for materials with thermal conductivity lower than $25 \mathrm{Wm}^{-1} \mathrm{~K}^{-1}$ [7]. With the development of ceramic substrates, thermal conductivity of some ceramic substrates even exceeds that of ordinary metal materials. With the purpose of quickly detecting the thermal conductivity of ceramic substrate at workshop, it is worthy to evaluate the possibility of utilizing hot wire method in fine ceramics. In this paper, both hot-wire method and laser-flash method were adopted in turn to measure the thermal conductivity of several fine ceramics. The experiment results are listed in Table 2, in which $\lambda_{1}$ and $\lambda_{2}$ stand for the mean thermal conductivity values of hot-wire method and laser-flash method respectively.

Fig. 1 shows the measurement results of different composites by hot-wire method and laser-flash method respectively. From Fig. 1, it can be seen that no matter what reinforcing phase the composites contain, the measurement results by hot-wire method and by laser-flash method are of great difference. The result is obviously outside the scope of allowed error $(5 \%-10 \%)$ by hotwire method [13].

Table 2. Thermal conductivity measured by hot-wire method and laser-flash method $\left(\mathrm{W} \cdot \mathrm{m}^{-1} \mathrm{~K}^{-1}\right)$

\begin{tabular}{|c|c|c|c|}
\hline No. & $\lambda_{1}$ & $\lambda_{2}$ & $\lambda_{1} / \lambda_{2}$ \\
\hline S1 & 3.46 & 4.71 & 0.734 \\
\hline S2 & 3.66 & 5.06 & 0.723 \\
\hline S3 & 4.56 & 6.41 & 0.711 \\
\hline S4 & 2.98 & 4.24 & 0.702 \\
\hline S5 & 1.66 & 2.31 & 0.718 \\
\hline S6 & 1.36 & 1.97 & 0.690 \\
\hline S7 & 3.87 & 5.44 & 0.711 \\
\hline S8 & 4.35 & 6.26 & 0.694 \\
\hline S9 & 5.02 & 7.12 & 0.705 \\
\hline S10 & 9.09 & 12.81 & 0.709 \\
\hline S11 & 11.39 & 15.93 & 0.715 \\
\hline S12 & 19.95 & 28.11 & 0.709 \\
\hline S13 & 10.54 & 14.44 & 0.729 \\
\hline S14 & 19.12 & 26.70 & 0.716 \\
\hline S15 & 27.22 & 38.91 & 0.699 \\
\hline
\end{tabular}

However, the calculation results demonstrate that no matter what the reinforcing phase (particle, whisker or fiber) is, the thermal conductivity values gained by hotwire method show approximately linear behavior with the results gained by laser-flash method. Fig. 2 shows the relation curve for ratio of thermal conductivity values by hot-wire method and by laser-flash method. The specific value of $\lambda_{1} / \lambda_{2}$ is around for 0.711 , the maximum deviation $(\sigma)$ is lower than $3 \%$. But, it can be seen that, the specific value of $\mathrm{Al}_{2} \mathrm{O}_{3} / 30$ glass $/ \mathrm{AlN}_{\mathrm{w}}(\mathrm{S} 4, \mathrm{~S} 5, \mathrm{~S} 6)$ has no obvious difference with that of $\mathrm{Al}_{2} \mathrm{O}_{3} / 30$ glass/ $/ \mathrm{AB}_{\mathrm{w}}$ (S7, S8, S9), although the varying trend of thermal conductivity values with whisker contents are in the opposite. The $\mathrm{Al}_{2} \mathrm{O}_{3} / 30$ glass $/ \mathrm{C}_{\mathrm{f}}$ (S10, S11, S12) and $\mathrm{Al}_{2} \mathrm{O}_{3} / 30$ glass $/ \mathrm{Cu}_{\mathrm{f}}$ (S13,S14,S15) has a similar result. The ratios between the values gained by hot-wire method and by laser-flash method seems to have no relation with the type of fiber or whisker. It can be concluded that the morphology (particle, whisker or fiber) of the reinforcing phase has a little affection on the result measured by these two methods within the range from $1.4 \mathrm{Wm}^{-1} \mathrm{~K}^{-1}$ to $28 \mathrm{Wm}^{-1} \mathrm{~K}^{-1}$ in the ceramic composites.

The above conclusion is obviously contrary with the traditional theory that hot-wire method is not proper for resin-based composite with fibers [17]. In this research, $\mathrm{Al}_{2} \mathrm{O}_{3} / 30$ glass/whisker (fiber) samples contained various kinds of one-dimensional materials in high volume fraction. But the thermal conductivity values of $\mathrm{Al}_{2} \mathrm{O}_{3} / 30$ glass/whisker (fiber) measured by hot-wire method showed no evidently abnormal trend, compared with that of $\mathrm{Al}_{2} \mathrm{O}_{3} / 30$ glass/ $/ \mathrm{AlN}_{\mathrm{p}}$.

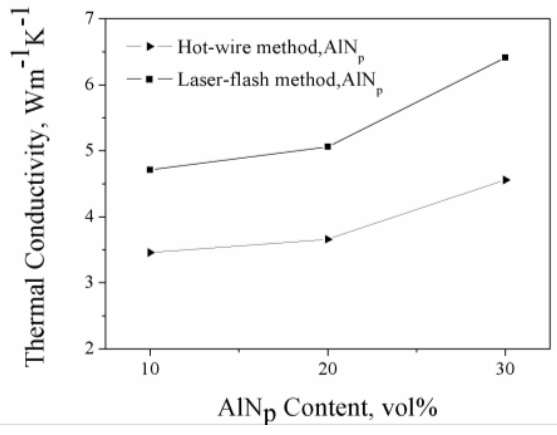

a

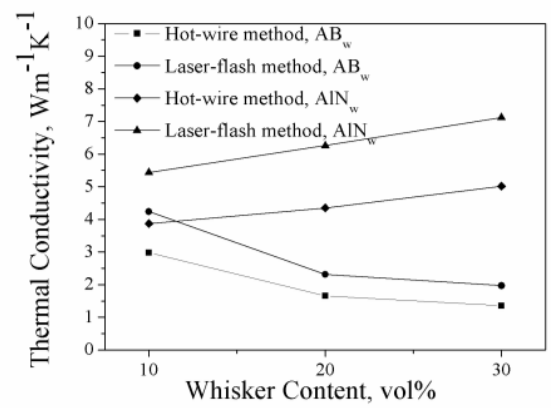

b

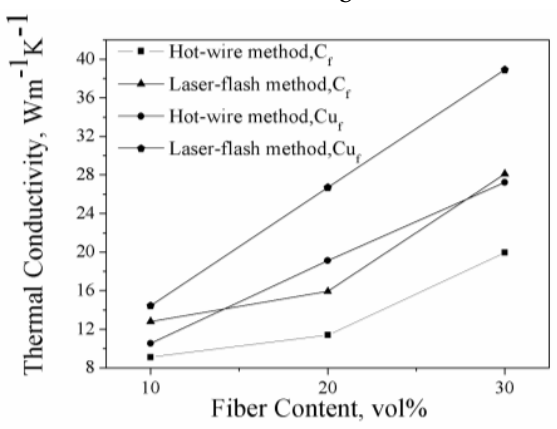

$\mathrm{c}$

Fig. 1. The comparison of measurement results between hotmethod and laser method: $\mathrm{a}-\mathrm{Al}_{2} \mathrm{O}_{3} / 30$ glass $/ \mathrm{AlN}_{\mathrm{p}}$; $\mathrm{b}-\mathrm{Al}_{2} \mathrm{O}_{3} / 30$ glass/whisker; $\mathrm{c}-\mathrm{Al}_{2} \mathrm{O}_{3} / 30$ glass /fiber

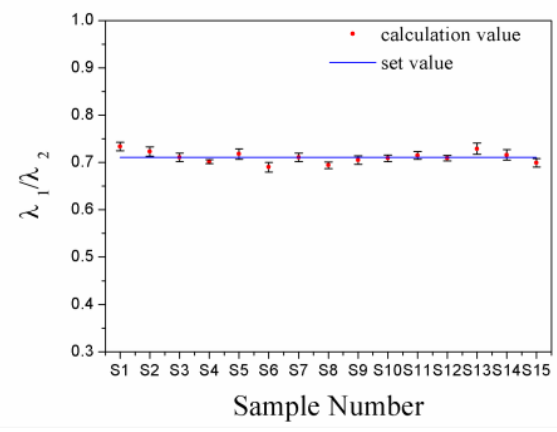

Fig. 2. The ratio of thermal conductivity measured by hot-wire method and laser flash method 


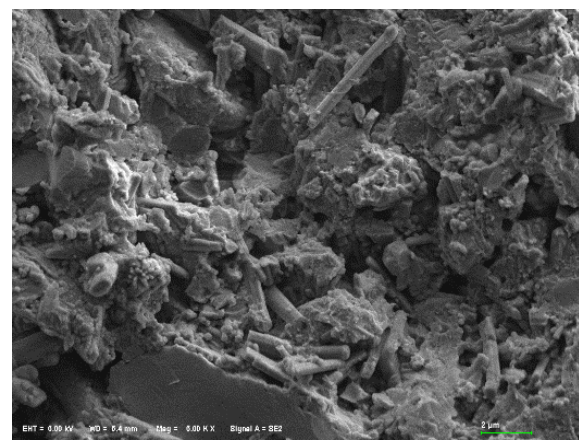

Fig. 3. Morphology of $\mathrm{Al}_{2} \mathrm{O}_{3} / 30$ glass $/ 30 \mathrm{AB}_{\mathrm{w}}$ ceramic composites sintered at $8800^{\circ} \mathrm{C}$

Fig. 3 shows the morphology of $\mathrm{Al}_{2} \mathrm{O}_{3} / 30$ glass $/ 30 \mathrm{AB}_{\mathrm{w}}$ ceramic composites sintered at $880{ }^{\circ} \mathrm{C}$. It can be found that the $\mathrm{AB}_{\mathrm{w}}$ whiskers randomly arranged without preferred orientation when the composite was under strictly multistep hot-pressing process. It could conclude that onedimensional material do not influence the measurement result by hot-wire method when it randomly aligns in 3D space in the composite matrix.

Based on the analysis above, the relationship between the measurement values of hot-wires method $\left(\lambda_{1}\right)$ and laserflash method $\left(\lambda_{2}\right)$ has been built up as Eq. 13 .

$\lambda_{2}=1.4 \lambda_{1}$.

It should be noted that the error of hot-wire method in this research $(\sim 40 \%)$ is much beyond the error range of declared $(5 \%-10 \%)$ [13]. The Hot Wire method is started for the thermal transport properties of fluids. For solids, the embedding of the wires between the two sample halves can lead to the thermal contact resistance, especially in the case of rigid samples. The contact resistance between wire sensor and sample surface plays an important role in measurement error of hot-wire method [4, 5]. Fine ceramics are much harder than resin or refractory. So, after traditional manual polishing, the sample's surface of fine ceramic would be hardly as smooth as that of resin or refractory in a certain area. The relative uneven surface of fine ceramic will lead to a big deviation between hot-wire method' data with laser flash method' data. Fortunately, the experimental results showed that there is a fixed coefficient relationship between hot-wire method' data and laser flash method' data, no matter pure ceramics or ceramic composite it is. So, it is possible to obtain the comparable thermal conductivity value for fine ceramic sample by the hot-wire method, when a surface roughness standard level is defined for the tested sample.

\section{CONCLUSIONS}

1. The difference between thermal conductivity results of fine ceramics by hot-wire method and by laser method is extremely remarkable.

2. In this research, thermal conductivity value of fine ceramics measured by hot-wire method has a certain positive relationship with that by laser-flash method.

3. In lab or workshop, it's possible to measure thermal conductivity of fine ceramics rapidly with convenience and low cost by modification the value measured by hot-wire method.

\section{Acknowledgments}

This work was supported by the Innovative Projects of Guangdong Education Department (No.38010202) and the Scientific Research Funds of Shantou University (07404846).

\section{REFERENCES}

1. Mohanram, A., Messing, G.L., Green, D.J. Densification And Sintering Viscosity of Low-Temperature Co-Fired Ceramics Journal of American Ceramic Society 88 2005: pp. 2681-2689. http://dx.doi.org/10.1111/j.1551-2916.2005.00497.x

2. Yuan, L., Liu, B., Shen, N., Zhai, T., Yang, D. Synthesis And Properties of Borosilicate/Aln Composite For Low Temperature CoFired Ceramics Application Journal of Alloys and Compounds 593 2014: pp. 34-40. http://dx.doi.org/10.1016/j.jallcom.2014.01.074

3. Wang, S.X., Liu, G.S., Yan, J.Y., Ye, J.X. Study of Al/SiC Package Substrate for High Power LED Key Engineering Materials 602 2014: pp. 285-289. http://dx.doi.org/10.4028/www.scientific.net/KEM.602-603.285

4. Assael, M.J., Antoniadis, K.D. Kakosimos, K.E., Metaxa, I.N. An Improved Applocation of The Transient Hot-Wire Techinique For The Absolute Accurate Measurement of The Themal Conductivity of Pyroceram 9606 up to $420 \mathrm{~K}$ International Journal of Thermophysics 29 2008: pp. $445-456$. http://dx.doi.org/10.1007/s10765-007-0333-5

5. Nunes dos Santos, W. Advance on the Hot Wire Technique Journal of the European Ceramic Society 28 2008: pp.15-20. http://dx.doi.org/10.1016/j.jeurceramsoc.2007.04.012

6. Nunes dos Santos, W. Thermal Properties of Melt Polymers by the Hot Wire Technique Polymer Testing 24 2005: pp.932-941.

7. Refractory Materials Determination of Thermal Conductivity Part 2: Hot-wire method (Parallel), ISO 8894-2:2007.

8. Jia, F.L., Li, L., Shi, Q. P. Principle of Measuring Thermal Conductivity Based on Steady-state Method Journal of Materials Science and Engineering Chinese 29 (4) 2011: pp. 609-613.

9. Schleirmacher, A.L. Uber Die Warmeleitung der Gas Wiederman' Annalen der Physik und Chemie 34 1888: pp. 625-637.

10. Van der Held, E.F.M., Van Drunen, F.G. A Method of Measuring the Thermal Conductivity of Liquids Physica XV 10 1949: pp. 865-881.

11. Haupin, W.E. Hot Wire Method for Rapid Determination of Thermal Conductivity American Ceramic Society Bulletin 39 (3) 1960: pp. 139-141.

12. Zhang, Z.J., Jin, W.G. Development and Application of the Hot Wire Method Journal of Jilin University of Technology (in Chinese) 2 1989: pp. 134-140.

13. Test Method Thermal Conductivity of Nonmetal Solid Material by Hot-Wire Method, GB/ T 10297-1998.

14. Yu, F., Zhang, X., Gao, G. Thermal Conductivity Measurement of Semitransparent Solids by Hot-Wire Technique International Journal of Thermophysics 21 (2) 2000: pp. 465-478. http://dx.doi.org/10.1023/A:1006695832162

15. Parker, W.J., Jenkins, R.J., Bulter, C.P., Abbott, G.L. A Flash Method of Determining Thermal Diffusivity Heat Capacity, and Thermal Conductivity Journal of Applied Physics 32 1961: pp. $1679-1684$

16. Tada, Y., Harada, M., Tanigaki, M., Eguchi, W. Laser Flash Method for Measuring Thermal Conductivity of LiquidsApplication To Low Thermal Conductivity Liquids Review of Scientific instruments 49 1978: pp. 1305-1314. http://dx.doi.org/10.1063/1.1135573

17. Buongiorno, J., Venerus, D.C., Prabhat, N., McKrell, T., Townsend, J. A Benchmark Study on the Thermal Conductivity of $\begin{array}{lll}\text { Nanofluids Journal of Applied Physics } 106 & 0\end{array}$ 2009: pp. 094312-1-094312-14. 